\title{
PRODUCTION OF CITRIC ACID FROM BANANA WASTE BY ASPERGILLUS NIGER
}

\author{
Dhandayuthapani .K, Thiyageswaran .G, Radeep Kumar .S \\ Dept. of Biotechnology, Sree Sastha Institute of Engineering and Technology \\ Chembarambakam Chennai, India \\ E-mail : 'kdpani\#bio@yahoo.co.in
}

\begin{abstract}
Citric acid commercially important product used in several industrial processes. Production of citric acid by Aspergillus niger from different varieties of banana peel such as green banana and yellow banana in surface culture process was studied. It was found that the maximum amount of citric acid $(87 \%)$ was produced from yellow banana peel used culture. Lower citric acid (45\%) was obtained from green banana peel used culture. By the extension of the fermentation (upto 25 days) resulted in an increase in citric acid concentration and biomass.
\end{abstract}

KEYWORDS : Citric acid, Aspergillus niger, Surface culture, Banana peel, Biomass, Fermentation.

\section{INTRODUCTION}

Citric acid ((2-hydroxpropane-1, 2,3-tricarboxylic acid, $\left.\mathrm{C}_{6} \mathrm{H}_{8} \mathrm{O}_{7}\right)$ is a white or translucent solid with a molecular weight of 192.12. It occurs as a natural constituent in citron, lime, pineapple, pear, peach and similar fruits. It is also found in animal tissues. The popular forms of citric acid are the anhydrous forms, the monohydrate and sodium salts of the acid. The end of nineteenth century it has been known as a natural plant substance. It is soluble in water with a pleasant taste, is the most important acid used in the food industries. It is a solid at room temperature, melts at $153^{\circ} \mathrm{C}$, and decomposes at higher temperatures. It is responsible for the tart taste of various fruits in which it occurs, e.g., lemons, limes, oranges, pineapples, and gooseberries. Until about 1920, all commercially needed acid was obtained from natural sources. It was produced from Lemon and Limejuices by King and Cheetam (1987).

With an estimated annual production of about 10 , 00,000 tons, citric acid is one of fermentation products with the highest level of production worldwide (Soccol et al., 2003). Considerable amount of citric acid are required in several industrial processes (Jianlong, 2000). The food industries consume about $70 \%$ of the total citric acid production, while other industries (Pharmaceuticals, Beverages, etc.,) consume the remaining 30\% (Pandey et al., 2001).

Before the development of fermentation technology, citric acid was obtained by extraction from the juices of citrus fruits (eg. Lemon), and later from pineapple wastes. Today most of the commercial citric acid is obtained by microbial fermentation process. As a result, the process of extraction this acid from the juices of certain citrus fruits became obsolete. Rohr et al., (1983) reported that citric acid can be produced by fermentation process using species of microorganisms namely Aspergillus niger, a fungus which was used commercially for the first time in 1923.
There has been an increasing trend towards efficient utilization of agro-industrial residues and byproducts (Soccol and Vandenberghe, 2003). Many of them have been studied with solid-state fermentation techniques for their potential use as substrates for citric acid production (Vandenberghe et al., 2000b). A cost reduction in citric acid production can be achieved by using less expensive substrates, such as apple and grape pomace, carrot waste, carob pod, orange and pineapple waste, cassava bagasse, okara (soy residue), coffee husk, kiwifruit peel, mussel processing waste, rice and wheat bran (Hang and Woodams, 1984, 1985, 1987; Aravantinos-Zafiris et al., 1994; Khare et al., 1995; Pandey et al., 2000; Soccol et al., 2003). Banana is one of the most important major fruit crops grown. In respect of area and production, it ranks second only to mango. The banana culture in India is as old as Indian civilization. Considering the nutritive value and fruit value of bananas, it is the cheapest among all other fruits. Considering the year round availability of fruits, unlike the seasonal availability of other tree fruits, it has become an inevitable necessity in any household, for all functions. The peel of banana was a rich source of water, Sugar, Protein, Fat, Fiber, tannin, carotene, pigments etc.

The influence of types and concentration of sugars (Hossain et al, 1984; Xu et al, 1989), chelating effects on metal ions (Roukas, 1998), ammonium nitrate and aeration (Bayraktar and Mehmetoglu, 2000) on Citric acid production by Aspergillus niger have also been studied. Citric acid is marketed as citric acid-1-hydrate or as anhydrous citric acid.

The aim of the present work was production of citric acid by $A$. niger using different varieties of banana peel as substrate. 


\section{MATERIALS AND METHODS}

\section{Microorganism and Inoculum}

A strain of Aspergillus niger was grown in Potato Dextrose Agar (PDA) slants at $28^{\circ} \mathrm{C}$ for seven days. Slants were preserved at $4^{\circ} \mathrm{C}$ for up to two months.

The spores of $A$. niger were produced in $250 \mathrm{ml}$ Erlenmeyer flasks containing $40 \mathrm{ml}$ PDA medium. The medium was inoculated with spores from the stock culture and incubated at $28{ }^{\circ} \mathrm{C}$ for seven days. The spores were recovered by stirring using a solution of Tween $800.01 \%$. The suspension obtained, containing $10^{8}$ spores $/ \mathrm{ml}$, was stored at $4^{\circ} \mathrm{C}$ for up to seven days.

\section{Fermentation media}

Banana peel from different varieties of banana like green (Musa canabalisa), yellow (Musa Paradisiacal) was used as the basal fermentation media. The extraction was extracted from banana peel by using sterilzed-distilled water. With the banana peel extraction $\mathrm{NH}_{4} \mathrm{NO}_{3}-0.32 \mathrm{~g} /$ $100 \mathrm{ml}, \mathrm{CaH}_{2} \mathrm{PO}_{4}-0.06 \mathrm{~g} / 100 \mathrm{ml}, \mathrm{MgSO}_{4} \cdot 7 \mathrm{H}_{2} \mathrm{O}-0.10$ $\mathrm{g} / 100 \mathrm{ml}, \mathrm{ZnSO}_{4} \cdot 5 \mathrm{H}_{2} \mathrm{O}-0.01 \mathrm{~g} / 100 \mathrm{ml}$, and Iron -0.20 $\mathrm{g} / 100 \mathrm{ml}$ were added to fermentation media. Surface liquid culture fermentation process was carried out in a $500 \mathrm{ml}$ Erlenmeyer flask containing $100 \mathrm{ml}$ media. Each flask was inoculated with the given spore suspension and incubated at $30^{\circ} \mathrm{C}$ for up to 25 days. The initial $\mathrm{pH}$ of the fermentation culture was adjusted to 3 using $1 \mathrm{~N}$ of $\mathrm{HCl}$ and/or $\mathrm{NaOH}$.

\section{Citric acid Determination}

Citric acid was determined titrimetrically (AOAC, 1995) by using $0.1 \mathrm{~N} \mathrm{NaOH}$ and phenolphthalein as indicator and calculated as \% according to the following formula:

$$
\% \text { Citric acid }=\text { Normality X Volume of } \mathrm{NaOH} \text { X Equiv. Wt. of CA }
$$

\section{Biomass and pH Determination}

Biomass and $\mathrm{pH}$ values were determined according to AOAC (1995). To determine biomass, the whole fungal culture growth was filtered with whatman filter paper washed with distilled water and dried at 105 ${ }^{\circ} \mathrm{C}$ to constant weight. A result was expressed as $\mathrm{g} / \mathrm{L}$. Culture $\mathrm{pH}$ was measured by digital $\mathrm{pH}$ meter.

\section{RESULTS AND DISCUSSION}

Citric acid production in surface liquid culture with yellow and green banana peel is shown in Figure 1. The highest citric acid ( $87 \%$ ) was produced in yellow banana peel used culture. In the green banana peel used culture was observed $45 \%$ of citric acid. The proximate composition of banana peel used as the basic fermentation media in this study was found to be $70 \%$ water (banana), 30\% sugar, 2.4\% Potassium, $0.76 \%$ Vitamin B6, $0.66 \%$ Carotene, $0.65 \%$ tannin. The carotene concentration is higher in yellow banana $(0.66 \%)$ then green banana $(0.56 \%)$. Factors affecting the production of citric acid by fermentation include the nutritional composition of the media, environmental conditions, deficiency of $\mathrm{Mg}$ and other metals, $\mathrm{pH}$, dissolved oxygen (Rouckas, 1997; Bayraktar and Mehmetoglu, 2000) and the influence of types and concentration of sugars (Hossain et al., 1984; Xu etal., 1989).

Biomass is a fundamental parameter in the characterization of microbial growth. Biomass was determined after $0,5,10,15,20$ and 25 day. The maximum biomass was observed on 20 day. These data are present in Figure 2.

Various parameters such as $\mathrm{pH}$ and temperature are used to optimize of citric acid production. The fermentation process was carried out at different temperatures $\left(10{ }^{\circ} \mathrm{C}, 15^{\circ} \mathrm{C}, 20^{\circ} \mathrm{C}, 25^{\circ} \mathrm{C}, 30^{\circ} \mathrm{C}, 35^{\circ} \mathrm{C}, 40\right.$ $\left.{ }^{\circ} \mathrm{C}\right)$. Maximum citric acid production was found at $30^{\circ} \mathrm{C}$. The results are shown in Figure 3 . Different pH $(2,2.5,3$, $3.5,4,4.55$ ) was used to optimize the production of citric acid. During the fermentation maximum citric acid production was observed at $\mathrm{pH} 3.5$ in the both banana peel used culture. The results are given in Figure 4. When increasing the $\mathrm{pH}$ citric acid production decreasing.

\section{CONCLUSION}

Citric acid production by $A$. niger with different banana peel in surface liquid culture was shown to hold promise. The utilization of banana peel observed for this process contributes to a reduction in environmental pollution and waste management also.

In this work high amount of citric acid was obtained in yellow banana peel culture then green banana peel culture, due to high amount of carotene present in yellow banana. When using the banana peel as a substrate for production of citric acid the optimum temperature and $\mathrm{pH}$ is must. In the present investigation found that optimum $\mathrm{pH}$ and temperature is 3.5 and $30^{\circ} \mathrm{C}$ respectively. 